\title{
A Miniaturized Meandered Dipole UHF RFID Tag Antenna for Flexible Application
}

\author{
Xiuwei Xuan, Lianrong Lv, and Kun Li \\ Tianjin Key Laboratory of Film Electronic and Communication Device, Tianjin University of Technology, Tianjin 300384, China \\ Correspondence should be addressed to Xiuwei Xuan; xiuweixuan@163.com
}

Received 29 February 2016; Revised 27 April 2016; Accepted 3 May 2016

Academic Editor: N. Nasimuddin

Copyright (C) 2016 Xiuwei Xuan et al. This is an open access article distributed under the Creative Commons Attribution License, which permits unrestricted use, distribution, and reproduction in any medium, provided the original work is properly cited.

\begin{abstract}
A miniaturized meandered dipole antenna for UHF RFID tag is proposed. Different resonance frequencies and impedance can be achieved by adjusting the number of the meanders, which can help to reduce the size of the antenna. Due to the radiation patches, the input impedance of the antenna can be flexibly tuned in a large scale. The proposed antenna is printed on polyethylene (PET) substrate with a total volume of $48 \mathrm{~mm} \times 13.7 \mathrm{~mm} \times 0.5 \mathrm{~mm}$. Modeling and simulation results show that the reflection coefficient of the antenna is less than $-15 \mathrm{~dB}$ at $860-960 \mathrm{MHz}$. Experimental studies demonstrate that the minimum threshold power of the antenna is between 23 and $26 \mathrm{dBm}$ and the measured read range is 3-4 m.
\end{abstract}

\section{Introduction}

Radio Frequency Identification (RFID) is a noncontact automatic identification and data acquisition technology that uses radio waves. With the excellent features, such as no line-of-sight requirement, long operating range, and working under harsh environment, RFID is widely used in various information systems. Ultrahigh frequency (UHF) RFID has many advantages compared to low-frequency system, such as longer read range and faster data rate and programmability. UHF RFID technology has become popular in everyday life. A typical RFID tag consists of an antenna and an integrated circuit chip. UHF RFID system involves electromagnetic interaction between the antenna of tag and reader. Backscattering modulation will have good performance when the microchip matches its internal load to the antenna $[1,2]$. The tag's antenna plays a key role in the system performance, such as read range, the power consumption of the microchip, and the overall size of the tag [3]. Since most UHF RFID tags are attached onto size-constrained objects, it is necessary to design small-geometry antennas with good radiation efficiency. To reduce the size of antenna, there are two strategies: meandering and inverted-F structures.
In order to reduce the size of the planar inverted-F antenna (PIFA), Zhang and Long embedded a slotted viapatch in the middle layer, which made the antenna input impedance flexibly tuned in a large scale [4]. However, the dual-layer antenna is complex for large scale production.

As proposed in [3], to operate on a plurality of materials for ubiquitous applications, antenna with sufficient bandwidth is necessary. The designed antenna can be mounted on a wide variety of dielectric materials of arbitrary thickness. As the permittivity increased, the resonance frequency decreased and the reflection coefficient increased, due to the amplitude-scaling factor. Microstrip antenna often reduces the antenna size by using dielectric slab with a high permittivity or increases communication frequency [5]. However, due to the limited bandwidth and large structure, microstrip antennas are not suitable for some applications. Hence, it is desirable to design small low cost, low profile antenna for simple production process [6]. According to Marrocco [2], the layout of the T-match has a considerable effect on the impedance of antenna. We adopt a T-match network to get a broadband performance.

This paper concentrates on the design of an electrically small flexible tag antenna with high efficiency, simple structure, and low cost. By changing the structure of dipole, we can 


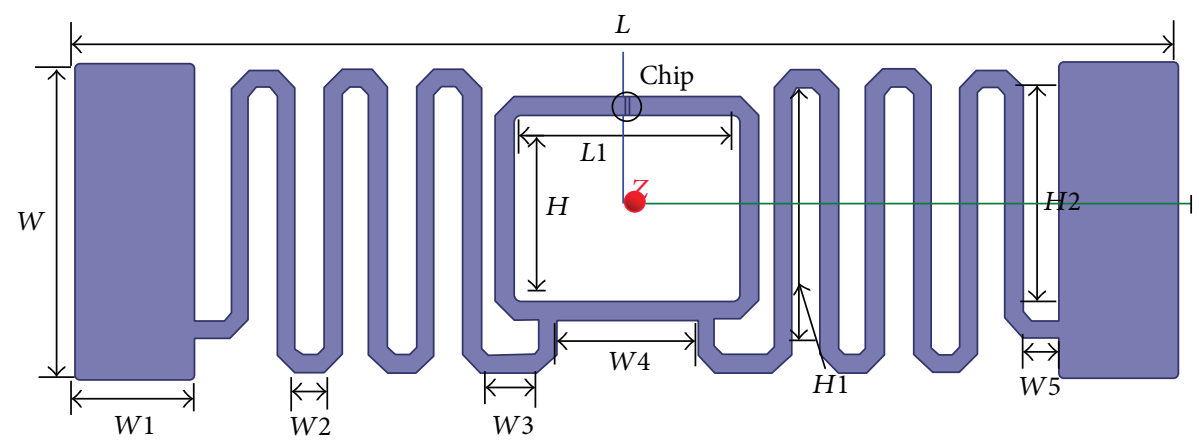

FIGURE 1: Structural configuration of the proposed antenna.

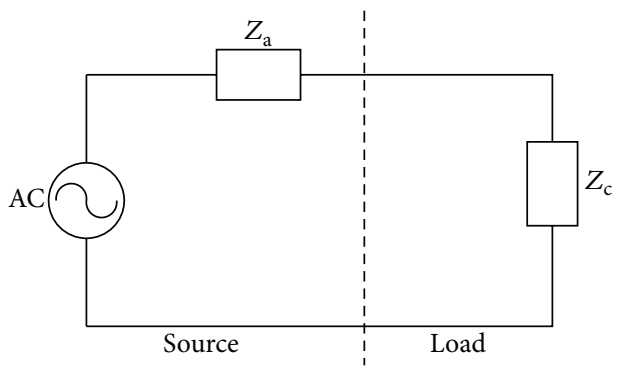

FIGURE 2: The equivalent circuit with two complex impedance instances.

adjust the input impedance of the antenna, so it can match its impedance to the microchip.

\section{Antenna Configuration}

In this section, we present a miniaturized UHF RFID tag antenna with a similar structure to that of 9662, manufactured by Alien Technology. The structural configuration of the antenna is illustrated in Figure 1. The antenna consists of a loop for feeding, a meandered dipole, and two radiators. The coupling between the loop and the dipole is adjusted by the distance between them and the size of loop [7].

The input impedance of the antenna in Figure $1, Z_{\mathrm{a}}$, is given by

$$
Z_{\mathrm{a}}=R_{\mathrm{a}}+j X_{\mathrm{a}}=Z_{\text {loop }}+\frac{(2 \pi f M)^{2}}{Z_{\mathrm{md}}}+Z_{\mathrm{rad}},
$$

where $Z_{\text {loop }}, Z_{\text {md }}$, and $Z_{\text {rad }}$ are the individual impedance of the loop, meandered dipole, and radiator, respectively. $M$ is the mutual inductance between the loop and meandered dipole.

We can see the tag as a one-port network, shown in Figure 2, which represents an antenna-chip circuit with complex source and load impedance. The power reflection coefficient between the antenna and chip $\left|S_{11}\right|^{2}$ shows what fraction of the maximum power available from the generator is not delivered to the load:

$$
\left|S_{11}\right|^{2}=\left|\frac{Z_{\mathrm{c}}-Z_{\mathrm{a}}^{*}}{Z_{\mathrm{c}}+Z_{\mathrm{a}}}\right|^{2}, \quad 0 \leq\left|S_{11}\right|^{2} \leq 1,
$$

where $Z_{\mathrm{c}}=R_{\mathrm{c}}+j X_{\mathrm{c}}$ is the chip impedance and $Z_{\mathrm{a}}=R_{\mathrm{a}}+j X_{\mathrm{a}}$ is antenna impedance. $Z_{\mathrm{a}}^{*}$ is the conjugate of $Z_{\mathrm{a}}$.

The power transmission coefficient $\tau$ is given by [8]

$$
\tau=1-\left|S_{11}\right|^{2}=1-\left|\frac{Z_{\mathrm{c}}-Z_{\mathrm{a}}^{*}}{Z_{\mathrm{c}}+Z_{\mathrm{a}}}\right|^{2}=\frac{4 R_{\mathrm{c}} R_{\mathrm{a}}}{\left|Z_{\mathrm{c}}+Z_{\mathrm{a}}\right|^{2}} \leq 1 .
$$

The activation distance of the tag $r$ can be calculated using Friis free-space formula as [8]

$$
r=\frac{\lambda}{4 \pi} \sqrt{\frac{P_{\mathrm{t}} G_{\mathrm{t}} G_{\mathrm{r}} \tau}{P_{\mathrm{th}}}}
$$

where $\lambda$ is the wavelength, $P_{\mathrm{t}}$ is the power transmitted by the reader, $G_{\mathrm{t}}$ is the gain of the transmitting antenna, $G_{\mathrm{r}}$ is the gain of the receiving tag antenna, and $P_{\text {th }}$ is the minimum threshold power to activate the RFID tag chip.

The impedance matching between the antenna and the chip is the primary factor that affects the performance of the antenna. To match the input impedance to the complex impedance value of Higgs-3, a meandered dipole and inductively coupled feed are utilized. The antenna is printed on PET substrate with a thickness of $0.5 \mathrm{~mm}$, a relative permittivity of 2.25 , and a dielectric loss tangent of 0.001 . The antenna is designed to conjugately match the passive IC chip of Alien Higgs-3 at around $920 \mathrm{MHz}$. We choose etched aluminum to manufacture the antenna.

2.1. Antenna with Different Number of Meanders. In order to validate the design procedure, antennas with different 


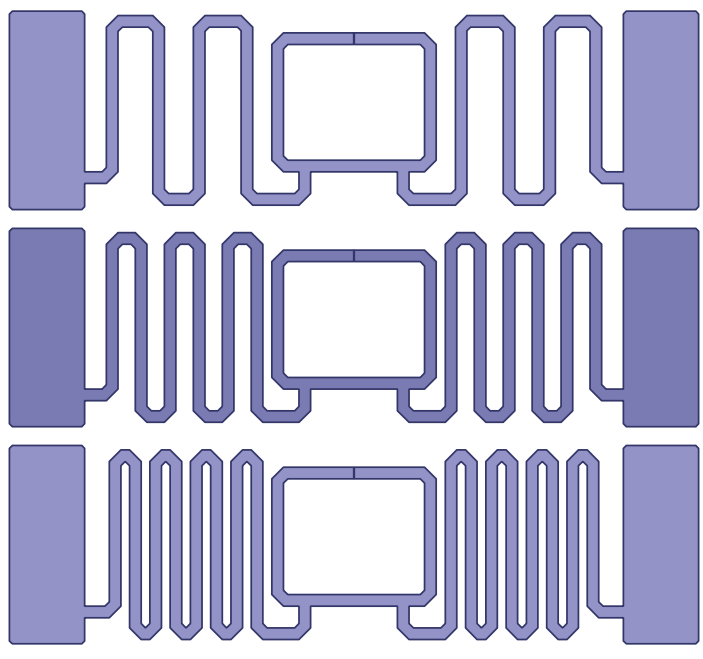

(a) The number of meanders $n$ is 2,3, and 4, respectively

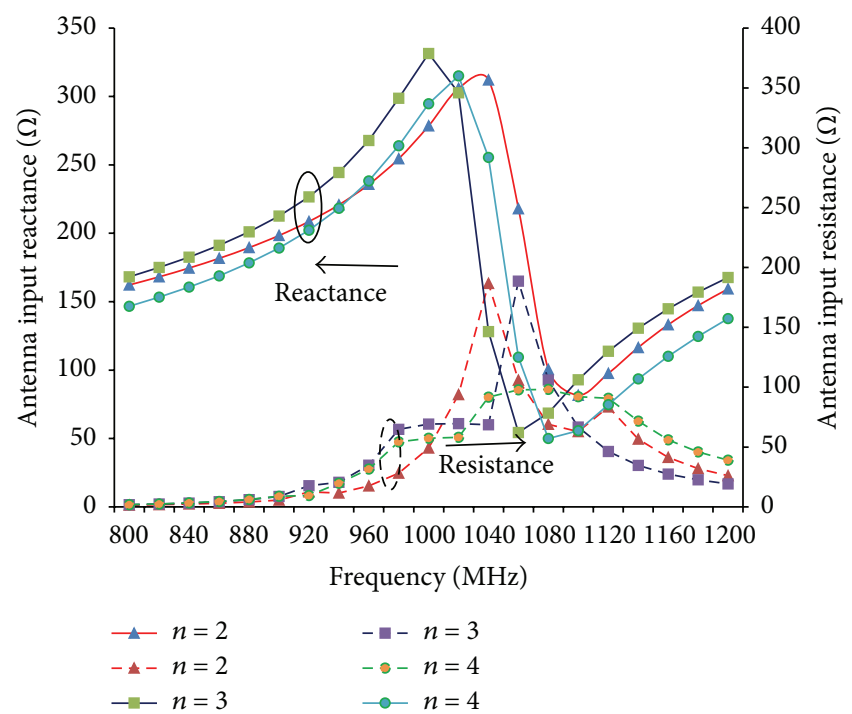

(b) Input impedance

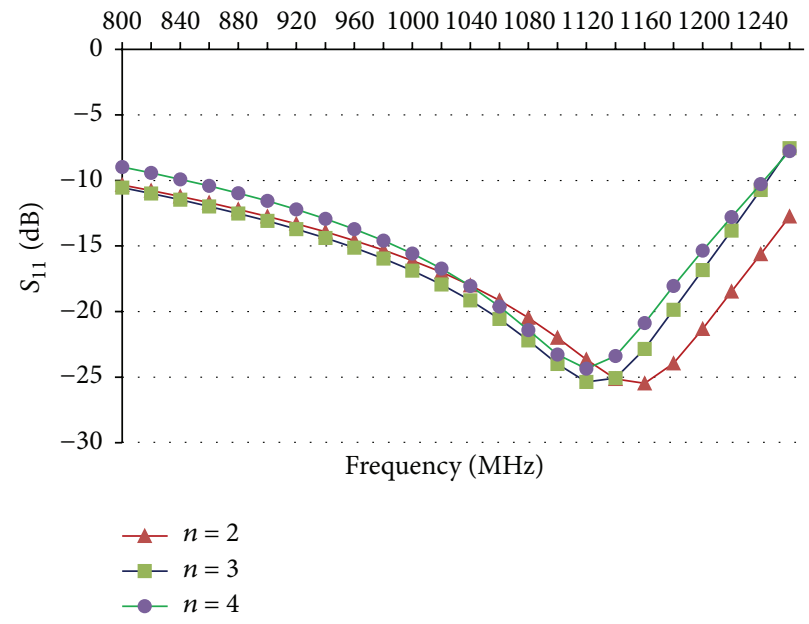

(c) Reflection coefficients

FIGURE 3: Simulated input impedance and reflection coefficients of tag antenna with different meanders.

number of meanders are modeled and simulated using fullwave simulator Ansoft HFSS. $n$ represents the number of the meanders. Figure 3 illustrates the antenna input impedance and reflection coefficients when $n=2,3,4$, respectively.

In Figure 3(a), the three antennas have the same total size with different number of meanders. Figure 3(b) shows the impedance characteristic of the three antennas. We can discover that the number of meanders could effectively tune the input impedance of the antenna. Figure 3(c) indicates the corresponding reflection coefficient of $S_{11}$. It can be seen that the $-3 \mathrm{~dB}$ bandwidth stretches across $860-960 \mathrm{MHz}$, which covers the entire UHF RFID band. As the number of meanders increases, the distances between them become closer and cause more offset coupling. According to Expression (1), the impedance of the meandered dipole $Z_{\mathrm{md}}$ decreases. That is to say, by independently adjusting $n$, the conjugate impedance matching different microchips can be easily realized.
2.2. Antenna with Different Radiators. Figure 4 illustrates the input impedance and reflection coefficients of antennas with different radiators when $n=3$. The first antenna does not have a radiator. The second antenna has a radiator with width $W 1=2.6 \mathrm{~mm}$, while the third antenna has a radiator with width $W 1=5.2 \mathrm{~mm}$. Since a larger radiator has greater impedance, we can easily control the antenna impedance and $S_{11}$ by changing the width of the radiator, which can be proved by Figures 4(b) and 4(c). Noting that impedance increases with $W 1$, we can get conjugate impedance matching different microchips by adjusting $W 1$. Similarly, different resonant frequencies and $-3 \mathrm{~dB}$ bandwidth can also be realized with different $W 1$.

2.3. Antenna with Different Size of Loops. Figure 5 illustrates the input impedance and reflection coefficients of antennas with different size of loop when $n=3$. The first antenna 


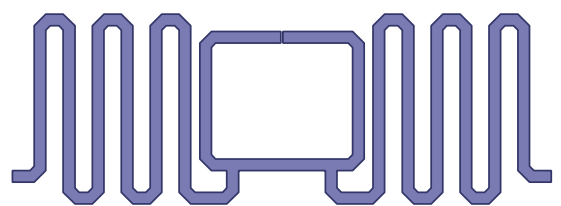
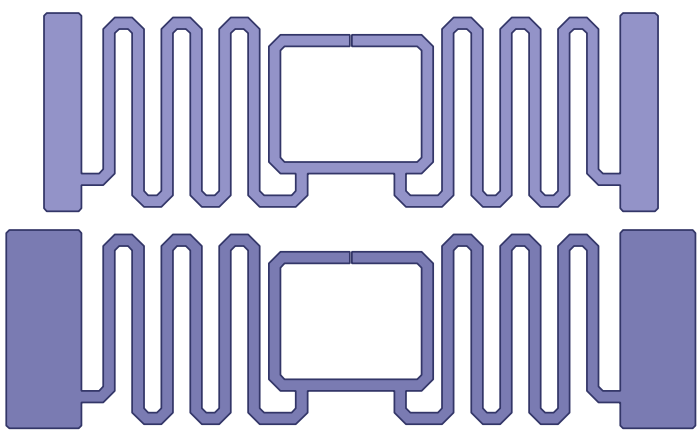

(a) The width of radiators $W 1$ is $0 \mathrm{~mm}, 2.6 \mathrm{~mm}$, and $5.2 \mathrm{~mm}$, respectively

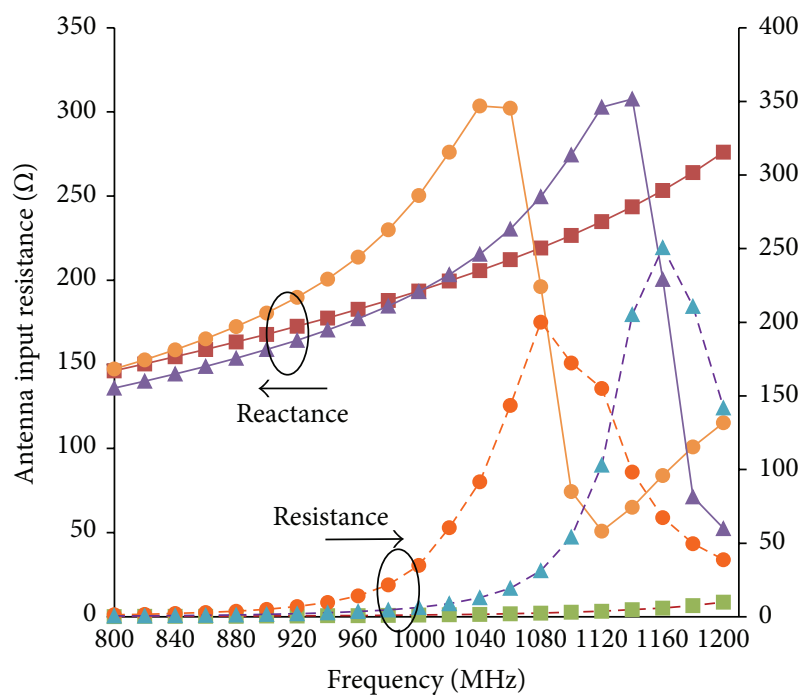

$$
\begin{aligned}
-W 1 & =0 & & -W 1=5.2 \mathrm{~mm} \\
-W 1 & =0 & \rightarrow W 1 & =2.6 \mathrm{~mm}
\end{aligned}
$$$$
\rightarrow W 1=5.2 \mathrm{~mm} \quad-\quad-W 1=2.6 \mathrm{~mm}
$$

(b) Input impedance

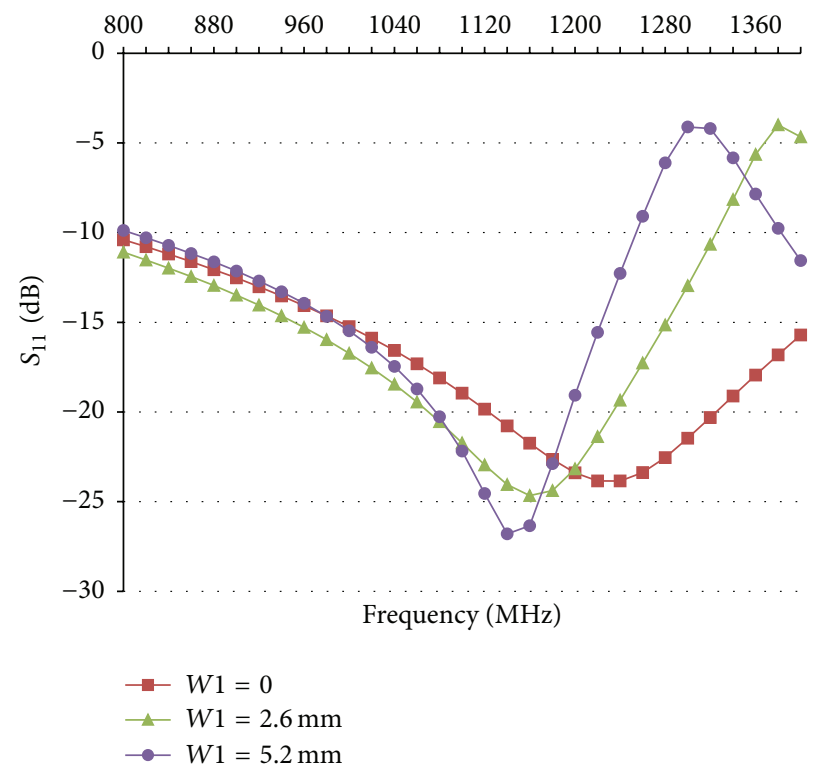

(c) Reflection coefficients

FIGURE 4: Simulated input impedance and reflection coefficients of tag antenna with different radiators.

has a loop with $L 1=4.35 \mathrm{~mm}$ and $H=3.4 \mathrm{~mm}$. The second antenna has a loop with $L 1=4.35 \mathrm{~mm}$ and $H=$ $7.4 \mathrm{~mm}$, while the size of the loop in the third antenna is $L 1=9.15 \mathrm{~mm}$, with $H=7.4 \mathrm{~mm}$. Figure 5(b) presents that the imaginary part of the antenna impedance is largely determined by the size of the loop. By comparing $S_{11}$ characteristics of the three antennas in Figure 5(c), we can discover the power reflection coefficient decrease when the size of loop increases. According to Expression (1), loop with larger size has higher impedance $Z_{\text {loop }}$. Meanwhile, the mutual inductance between the loop and meandered dipole will also increase. Therefore, the conjugate impedance matching different microchips can be easily realized by adjusting the size of loop.

\section{Antenna Design and Characteristics}

In this design, we fix the number of meanders $n$ at 3 and the width of the radiator $W 1$ at $5.2 \mathrm{~mm}$. The prototype antenna is designed for Alien Higgs-3 RFID chip, whose input impedance is $Z=(19-j 119) \Omega$ at $925 \mathrm{MHz}$. A photograph of the fabricated tag is shown in Figure 6. The relevant parameters of the antenna are as follows: $L=48 \mathrm{~mm}$, $W=13.7 \mathrm{~mm}, W 1=6.2 \mathrm{~mm}, W 2=1.2 \mathrm{~mm}, W 3=2.5 \mathrm{~mm}$, 

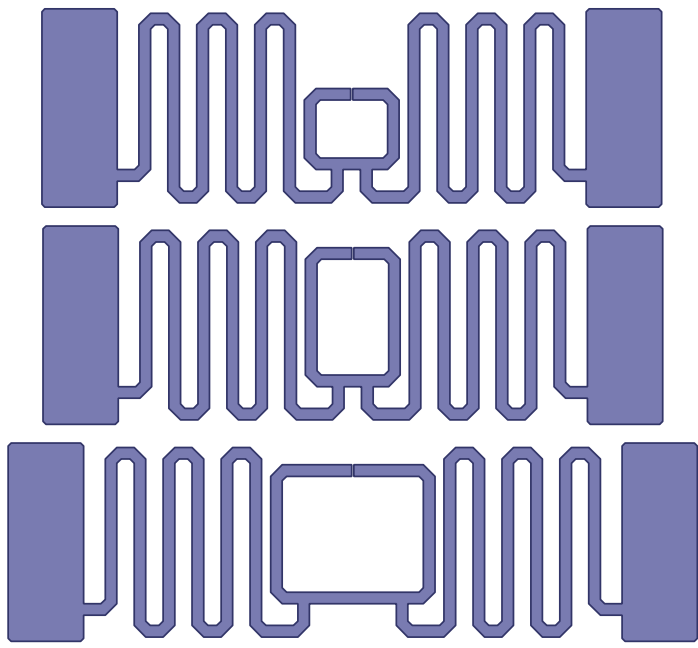

(a) Antennas with different size of loops

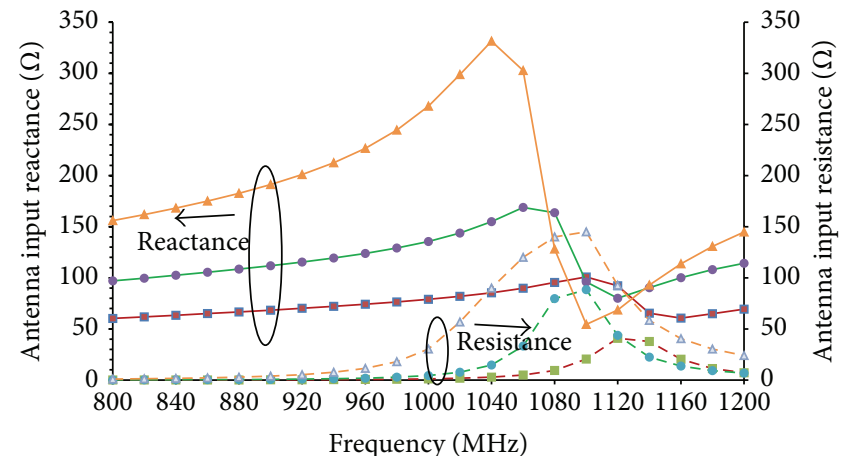

$\because L 1=4.35 \mathrm{~mm}, H=3.4 \mathrm{~mm}$

- - $L 1=4.35 \mathrm{~mm}, H=7.4 \mathrm{~mm}$

- $-L 1=4.35 \mathrm{~mm}, H=3.4 \mathrm{~mm}$

- $-L 1=9.15 \mathrm{~mm}, H=7.4 \mathrm{~mm}$

$\rightarrow L 1=4.35 \mathrm{~mm}, H=7.4 \mathrm{~mm}$

\- $L 1=9.15 \mathrm{~mm}, H=7.4 \mathrm{~mm}$

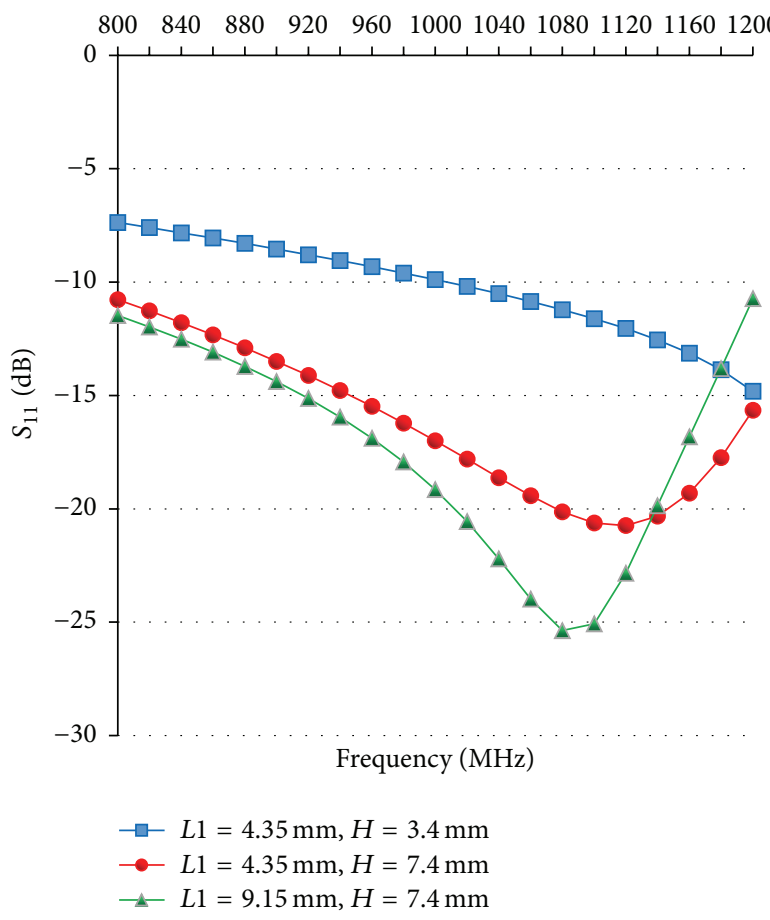

(c) Reflection coefficients

FIGURE 5: Simulated input impedance and reflection coefficients of tag antenna with different loops.

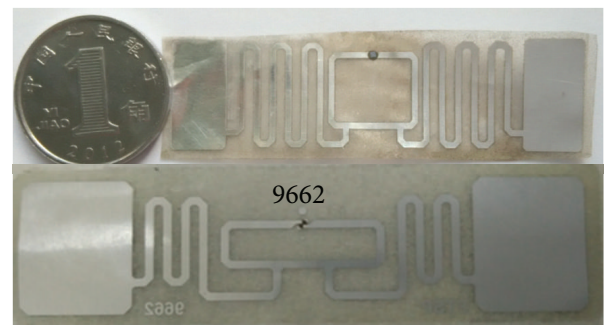

FIGURE 6: Photograph of the proposed RFID tag and 9662. 


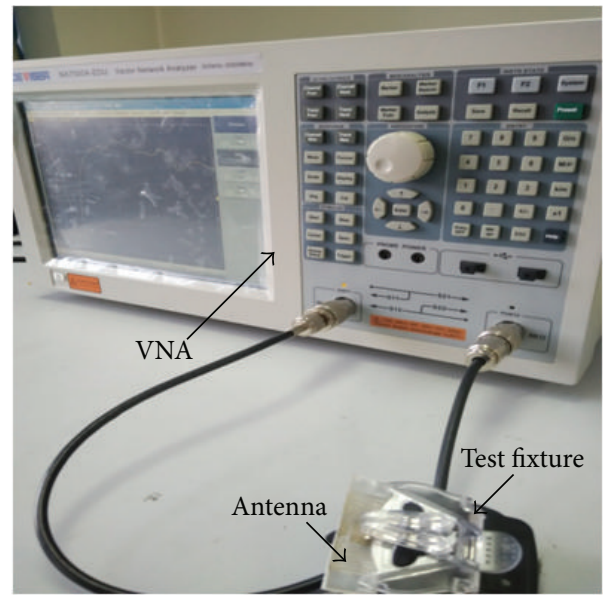

Figure 7: Measurement setup using VNA.

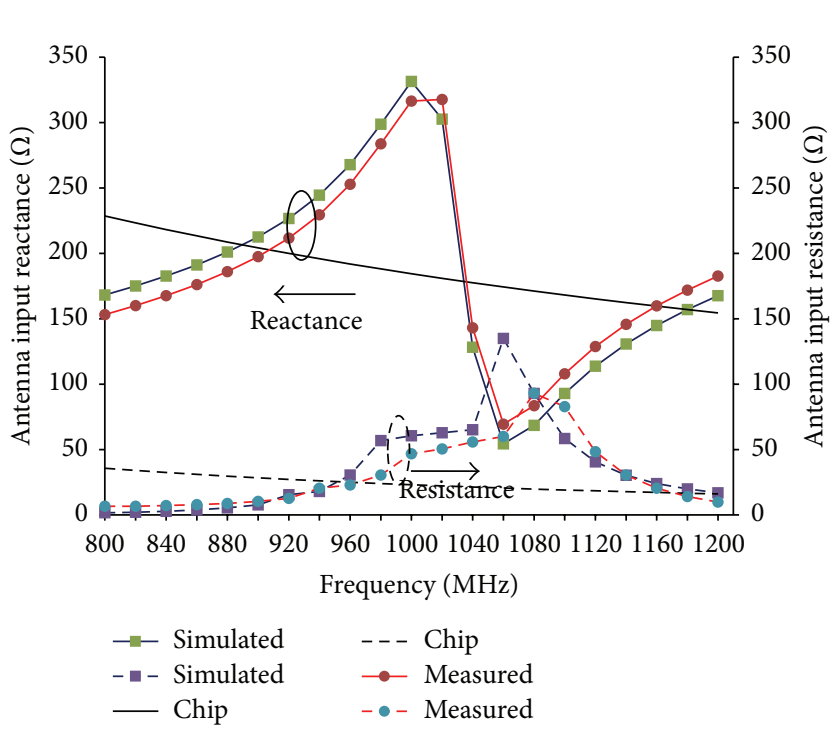

(a) Input impedance

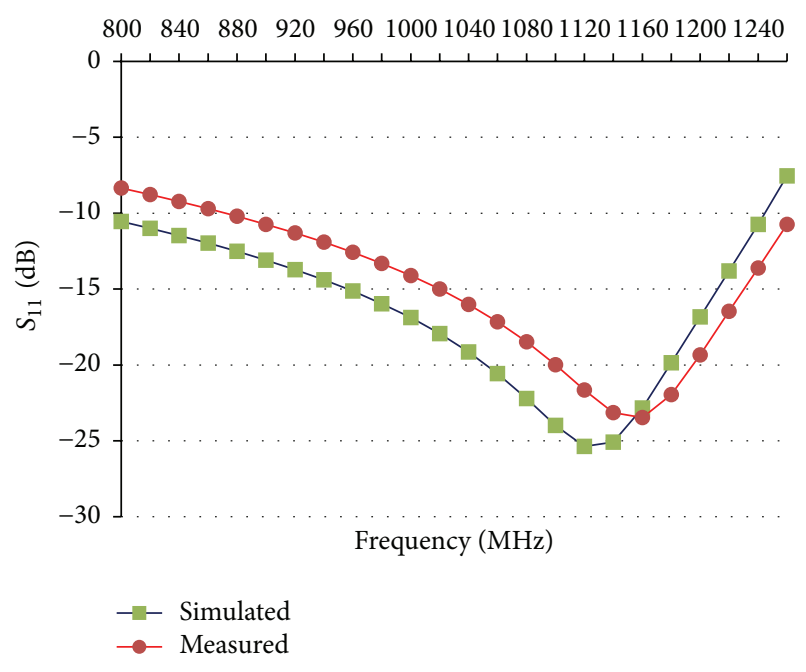

(b) Reflection coefficients of $S_{11}$

FIGURE 8: Impedance matching performance of the proposed antenna.

$W 4=6 \mathrm{~mm}, L 1=9.15 \mathrm{~mm}, H 1=11.2 \mathrm{~mm}, H 2=9.7 \mathrm{~mm}$, and $W 5=1.5 \mathrm{~mm}$. The overall size of our miniaturized tag is $48 \mathrm{~mm} \times 13.7 \mathrm{~mm} \times 0.5 \mathrm{~mm}$, while the size of 9662 is $69 \mathrm{~mm}$ $\times 16 \mathrm{~mm} \times 0.5 \mathrm{~mm}$

In order to verify the matching performance, the impedance measurement was carried out using vector network analyzer (VNA) and the port-extension technique proposed in [9]. The configuration of the measurement system is illustrated in Figure 7.

Figure 8 shows the impedance characteristic and the reflection coefficient of the proposed antenna. In Figure 8(a), solid line represents the reactance while dashed line represents the resistance, and chip represents the conjugate value of tag chip's impedance.

The minimum threshold power as well as read range of the tag was measured in an anechoic chamber using a circularly polarized reader antenna with an effective isotropic radiated power (EIRP) of 4 W. From Figure 9, we can discover that the minimum threshold power is between 23 and $26 \mathrm{dBm}$ over the entire UHF RFID band. Figure 10 shows that the measured read range of the proposed tag is between 3 and $4 \mathrm{~m}$. That is to say, the reading performance of the tag is stable over the entire UHF RFID band.

\section{Conclusion}

A miniaturized and flexible RFID tag antenna with a total volume of $48 \mathrm{~mm} \times 13.7 \mathrm{~mm} \times 0.5 \mathrm{~mm}$ is proposed for the UHF RFID band. Different radiation patches and number of meanders can be employed to help get diverse input impedance and small size characteristics. The simulation study of the antenna has been carried out with the help of HFSS, while the measurement study has been implemented in an anechoic chamber. Both the simulation and measurement results indicate that the impedance matching performance is acceptable, which implies that the proposed antenna is 


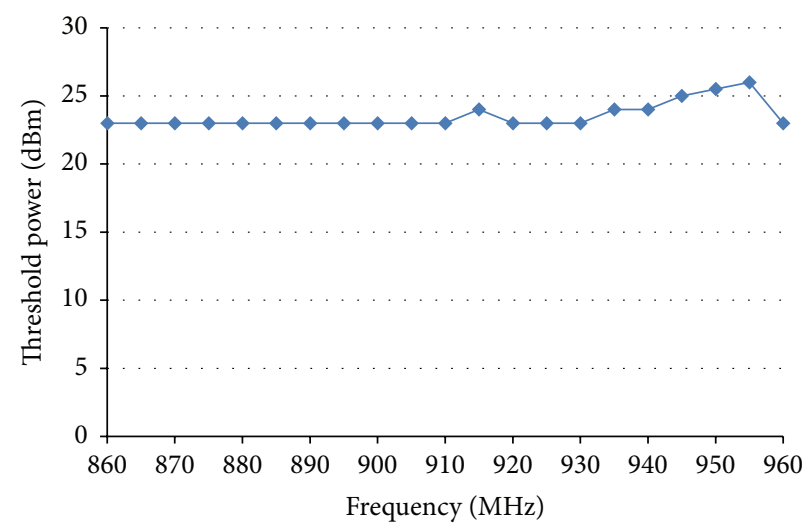

FIGURE 9: The minimum threshold power to activate the tag chip.

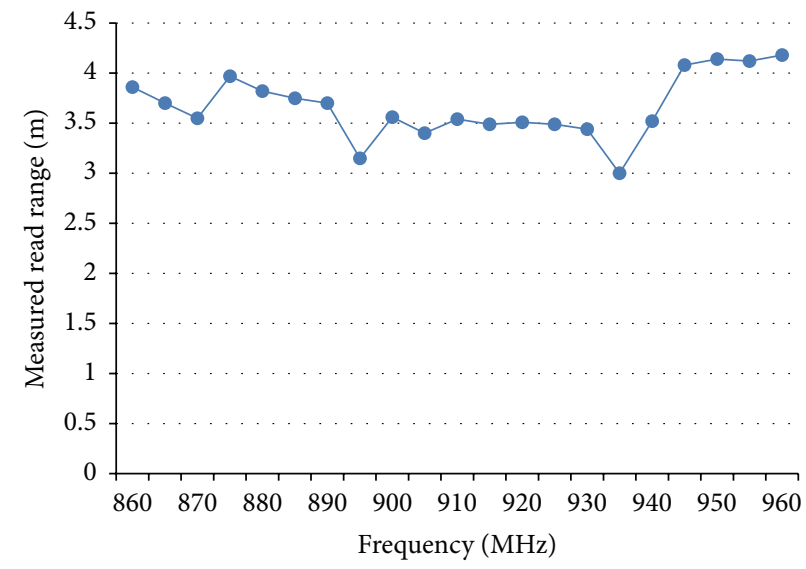

FIGURE 10: Measured read range of the proposed tag antenna.

a good candidate for miniaturized, flexible, and low-power consumption tags.

\section{Competing Interests}

The authors declare that they have no competing interests.

\section{Acknowledgments}

This work is supported by Natural Science Foundation of Tianjin (no. 13JCQNJC01300) and Tianjin Project of Science and Technology (no. 15ZLZLZF00300).

\section{References}

[1] S. X. Ta, I. Park, and R. W. Ziolkowski, "Crossed dipole antennas: a review," IEEE Antennas and Propagation Magazine, vol. 57, no. 5, pp. 107-122, 2015.

[2] G. Marrocco, "The art of UHF RFID antenna design: impedance-matching and size-reduction techniques," IEEE Antennas and Propagation Magazine, vol. 50, no. 1, pp. 66-79, 2008.

[3] S. Shao, R. J. Burkholder, and J. L. Volakis, "Design approach for robust UHF RFID tag antennas mounted on a plurality of dielectric surfaces [antenna designer's notebook]," IEEE
Antennas and Propagation Magazine, vol. 56, no. 5, pp. 158-166, 2014.

[4] J. Zhang and Y. Long, "A Miniaturized via-patch loaded duallayer rfid tag antenna for metallic object applications," IEEE Antennas and Wireless Propagation Letters, vol. 12, pp. 1184-1187, 2013.

[5] N. Sharma, A. K. Gautam, and B. K. Kanaujia, "Circularly polarized square slot microstrip antenna for RFID applications," International Journal of Microwave \& Wireless Technologies, 2015.

[6] B. Wang, "A compact antenna design for UHF RFID applications," Progress in Electromagnetics Research Letters, vol. 53, pp. 83-88, 2015.

[7] W. Choi, H. W. Son, C. Shin, J.-H. Bae, and G. Choi, "RFID tag antenna with a meandered dipole and inductively coupled feed," in IEEE Antennas and Propagation Society International Symposium (APS '06), pp. 619-622, Albuquerque, NM, USA, July 2006.

[8] J. Zhang and Y. Long, "A dual-layer broadband compact UHF RFID tag antenna for platform tolerant application," IEEE Transactions on Antennas and Propagation, vol. 61, no. 9, pp. 4447-4455, 2013.

[9] X. Qing, C. K. Goh, and Z. N. Chen, "Impedance characterization of rfid tag antennas and application in tag co-design," IEEE Transactions on Microwave Theory and Techniques, vol. 57, no. 5, pp. 1268-1274, 2009. 


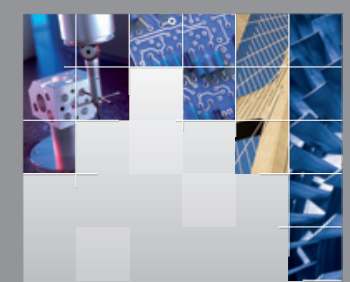

\section{Enfincering}
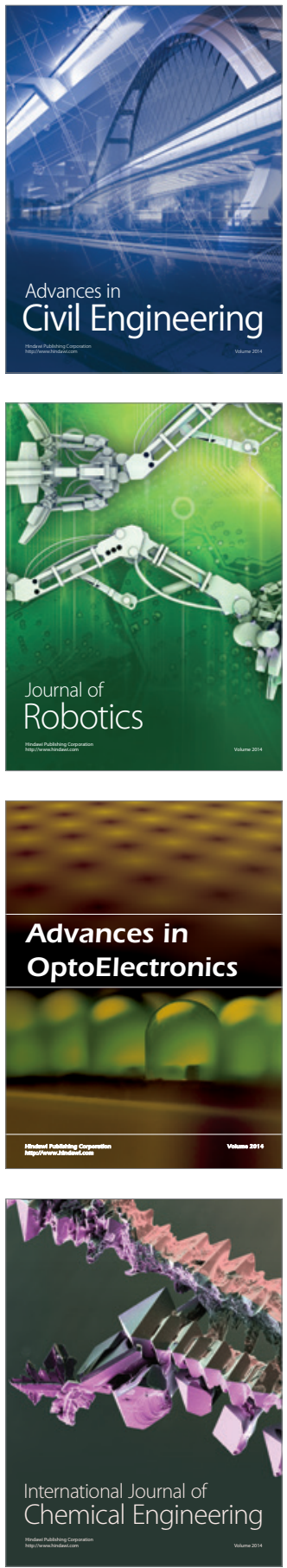

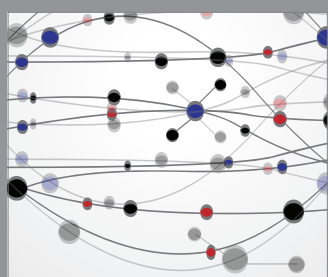

The Scientific World Journal

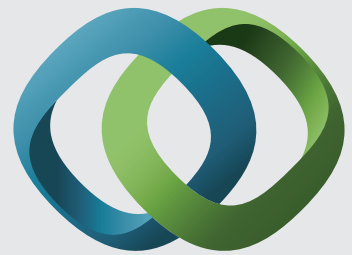

\section{Hindawi}

Submit your manuscripts at

http://www.hindawi.com
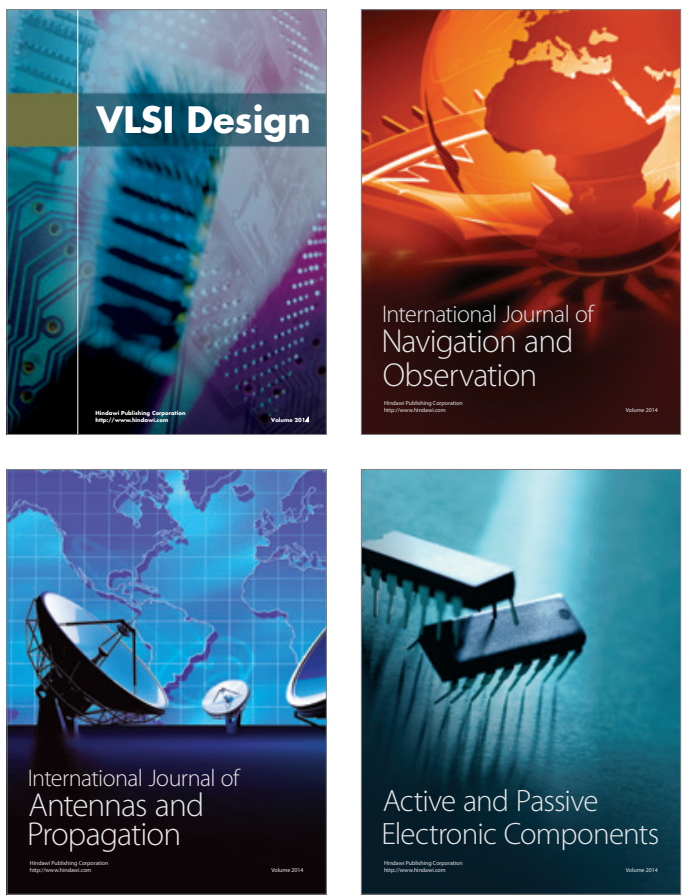
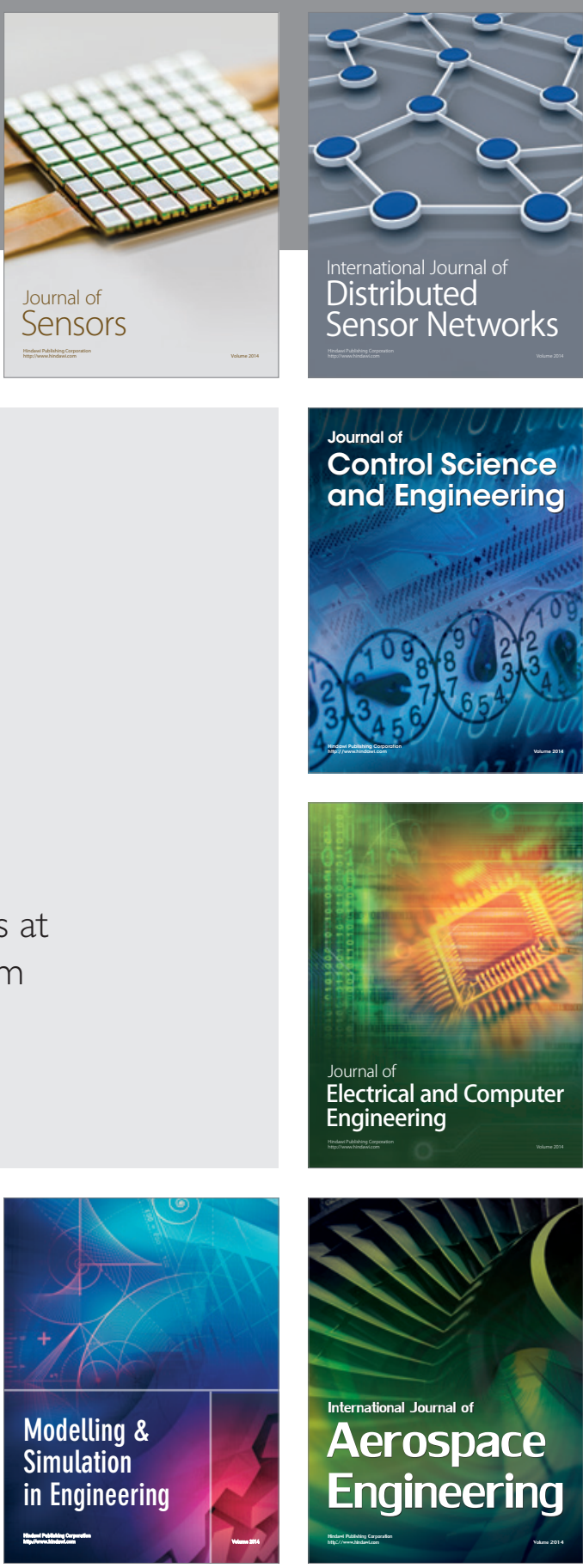

International Journal of

Distributed

Sensor Networks

Journal of

Control Science

and Engineering
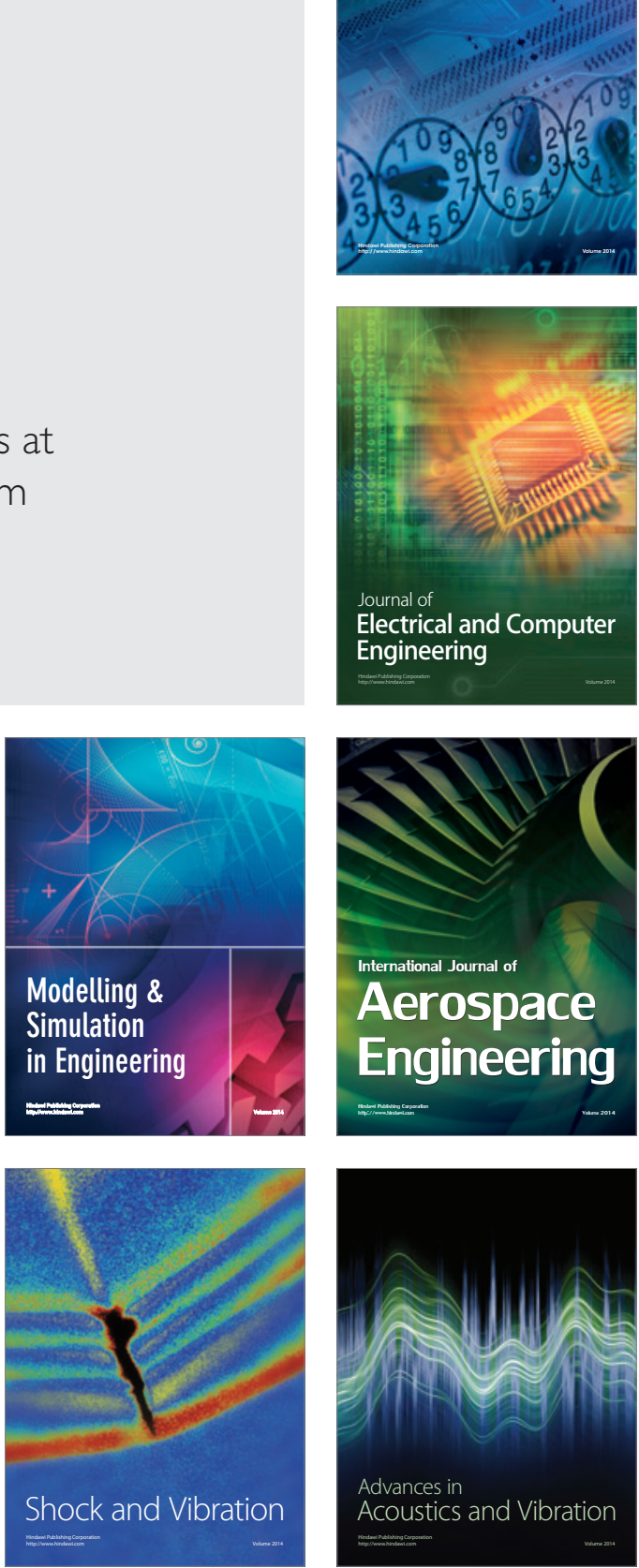